\title{
EDITORIAL: EDUCAÇÃO E CIÊNCIAS AMBIENTAIS
}

Christiano Nogueira

Emerson Joucoski

Este dossiê temático sobre a Educação e Ciências Ambientais nos agracia com trabalhos inéditos oriundos de várias instituições do país. A proposta deste dossiê foi motivada com o início das atividades do Programa de Pós-graduação em Ensino das Ciências Ambientais - Polo UFPR devido à discussões e debates entre docentes e discentes sobre a oportunidade de congregar trabalhos no contexto do Ensino das Ciências Ambientais. Nesse número especial, apresentamos trabalhos que abordam a educação e as ciências ambientais, metodologias e práticas pedagógicas na perspectiva interdisciplinar.

Este dossiê se inicia com o trabalho denominado "CONSTRUÇÃO DE INDICADORES PARA AVALIAÇÃO DO PROGRAMA MUNICIPAL DE EDUCAÇÃO AMBIENTAL DE SÃO CARLOS” das autoras Valéria Ghisloti Iared, Mayla Valenti, Mariangela Spadoto e Haydée Torres de Oliveira que nos traz uma proposta para desenvolver indicadores para avaliar políticas públicas em educação ambiental no Brasil. A Organização para a Cooperação e Desenvolvimento Económico (OCDE) defende que indicadores fazem parte de um ciclo político e contribuem para a formulação, implementação e avaliação de políticas, pois são variáveis que agregam ou simplificam os dados importantes, tornam visíveis ou perceptíveis os fenômenos de interesse e ainda quantificam, medem e comunicam as informações relevantes. A partir de encontros e oficinas com professoras(es), funcionárias(os) públicos(as), representante de ONGs e estudantes de universidades foram sugeridos 34 indicadores, cada um relacionado aos públicos atendido e à sua fonte de coleta de dados. As autoras consideram que o processo foi válido tanto para impulsionar o uso de indicadores para avaliação das políticas públicas em educação ambiental no município como para a formação das pessoas que participaram das oficinas. O trabalho se destaca pelo processo de construção de indicadores e elenca as difículdades que a temática encerra. Assim, pode incentivar e auxiliar na orientação de outras experiências de construção de indicadores para políticas públicas em educação ambiental.

A pesquisa de cunho teórico de autoria de Eliandra Farncielli Bini Jaskiw, Luis Fernando de Carli Lautert e Renata Gerhardt intitulado "EDUCAÇÃO, COMPLEXIDADE E AMBIENTE: UM DIÁLOGO POSSÍVEL RUMO AO BEM VIVER" faz um resgate histórico sobre a evolução do pensamento sistêmico, que tem como premissa de que o todo é maior do que a soma das partes. O texto se baseia nas evidências da complexidade dos fenômenos humanos e naturais, cita inúmeros autores que defendem que o real tece relações mútuas e possui influências recíprocas entre as partes e o todo em um mundo complexo. Surge, dentro desse contexto, o pensamento latino-americano do "Bem Viver" onde as ideias seguem a proposta da complexidade das relações e do homem como ser integrante da natureza, defendendo a sua indissociabilidade.

No artigo "ÁGUA E CIDADANIA: CONSTRUÇÃO DE CARTILHA DIGITAL NO ENSINO DE CIÊNCIAS" das autoras Amanda Cordeiro de Melo Souza, Klyvia Leuthier dos Santos e Walma Nogueira Ramos Guimarães nos traz outro tema transversal, a água, e o seu aprendizado usando o recurso educacional dos objetos de aprendizagem. O produto gerado da ação educacional foi uma cartilha digital. Nesse processo foram construídos mapas mentais e imagens que foram digitalizados para a construção da cartilha final. Todo o processo possibilitou que os estudantes avaliassem o conteúdo e as ilustrações da cartilha, colaborando para a sensibilização da importância da água.

Em "BIODIVERSIDADE: INICIATIVAS POPULARES DO MOVIMENTO ESTUDANTIL NACIONAL DA BIOLOGIA" de autoria de Rodrigo Ferraz Ramos, Suzana dos Santos de Souza, Riceli Gomes Czekalski, Anderson Machado Pavanelo, Ísis Caroline Siqueira Santos e Débora Leitzke Betemps o artigo encaminha uma discussão sobre da temática biodiversidade e, em paralelo, destaca algumas ações do movimento estudantil nacional da Biologia, a Entidade Nacional de Estudantes de Biologia (ENEBio), em defesa da biodiversidade e da vida. Entre as ações que a entidade apoia e colabora para a divulgação em nível nacional, e que corrobora com a ampliação da discussão da temática biodiversidade, destaca-se a denominada campanha permanente contra os agrotóxicos e pela vida. Assim, percebe-se que o movimento estudantil nacional da biologia promove um conjunto de iniciativas populares na defesa da biodiversidade e da vida. 
No artigo "PROJETO SOLO VIVO: EXPERIÊNCIAS COM SOLOS NA EDUCAÇÃO BÁSICA" a autora Maria Fernanda Lopes de Freitas apresenta uma proposta pedagógica desse tema transversal para ser aplicado aos estudantes da educação básica para que aprendam sobre a formação do solo, sua origem e estrutura, bem como as relações ecológicas nele recorrentes. A autora destaca a importância dos solos como componente essencial do meio ambiente e da vida e a necessidade de se conhecer mais sobre o tema e a sua conservação. Através da proposta de aulas práticas e experimentais do tipo "mão na massa" resgata-se a importante interação entre ser humano e natureza e põe em contato direto os sujeitos que aprendem sobre a natureza dos solos e seus componentes orgânicos e inorgânicos.

Em "STOP MOTION: A LINGUAGEM CINEMATOGRÁFICA E O PROCESSO DE ENSINO-APRENDIZAGEM ATRAVÉS DO CELULAR" de autoria de Daiana Maria Holz de Souza e Maurício de Souza, é apresentada uma descrição de um relato de experiência do uso do celular como ferramenta para a produção de imagens com finalidades pedagógicas, partindo da técnica cinematográfica de quadro-a-quadro (Stop Motion). O processo aconteceu na integração entre as disciplinas de Artes e Ciências com alunos do oitavo ano em 2018 no município de Matinhos - PR. No texto faz-se um resgate da relação entre educação, o cinema, a sala de aula, o celular e o uso de mídias e tecnologias que possam contribuir para a efetiva construção do conhecimento em sala de aula. Relata-se a concepção de possíveis novos rumos e perspectivas sobre o ensino de Artes e das Ciências na escola onde a interdisciplinaridade enriqueceu todo o processo de ensinoaprendizagem.

Uma boa leitura a tod@s.

Os Organizadores. 